\title{
EVOLUTIONARY EVALUATION OF ENERGY AND NANOTECHNOLOGY
}

\author{
RELATIONSHIP \\ Serhat Burmaoglu $\quad$ Sercan Ozcan ${ }^{2}$ \\ ${ }^{1}$ Izmir Katip Celebi University, Department of Economics and Administrative Sciences, Izmir, \\ Turkey, serhatburmaoglu@gmail.com \\ ${ }^{2}$ Bahcesehir University, Faculty of Engineering and Natural Sciences, Istanbul, Turkey, \\ sercan.ozcan@eng.bau.edu.tr
}

As a result of changing conditions in the world due to increasing population, scarce natural resources and climate change, there are increasing number of research activities in the areas of food, water and energy, which are critical for humanity. With the growing threat of pollution, global warming, and energy crises caused by countries' strong dependence on the dwindling supply of nonrenewable fossil fuels, the search for clean, sustainable and renewable alternative energy resources is one of the most urgent challenges to the sustainable development of human civilization [1]. According to Jones (2009), these challenges can be overcome by applying nanoscience and technology to the energy field [2].

Nanomaterials can be produced in a variety of material classes such as: carbon-based nanomaterials, nanocomposites, metals and alloys, and these classes can be produced with different shapes and properties. One of the interesting properties of such nanomaterials is their very high surface area per unit volume that leads to much higher surface activity than in the bulk material. This has potential for speeding up chemical reactions and catalysis and thus improving the efficiency of many processes. There are many applications of nanotechnologies in energy systems have been identified in various reviews as: 1) energy conversion, 2) energy storage, 3) energy transmission, and 4) energy use [3, 4].

The aim of the study is to analyze the relationship of energy and nanotechnology fields by using scientometric methods. For this study, Web of Science database was used with the help of lexical search query strategy. Nanotechnology and the keyword set that is applied by $[5,6]$ is used to gather data in related journals. To determine the energy journals experts in the energy field are further consulted and then the whole collection downloaded for last 10 years period. The collected data is analyzed by using text-mining techniques to understand the relationship and convergence between nanotechnology and energy fields. Finally, future collaboration opportunities are extracted and interpreted for this field.

Keywords: nanoenergy, nanotechnology, energy, scientometrics, bibliometrics, energy policy

\section{INTRODUCTION}


Growing energy demand and fast exhausting resources make governments and scientists challenge to find solutions for energy demand problem without releasing carbon dioxide into the atmosphere. This challenge may have answer within the nanotechnology developments. The improvements in nanotechnology lead many countries to take applications of nanotechnology in the energy field [7]. Especially, after some of the developed countries declared and get their energy policy crossed with nanotechnology, nanoenergy field became popular after 2000s. Sustainability and clean energy concepts also played important role and pressed governments to take action for mass generation of energy via nanotechnology. Moreover, nanotechnology as a general purpose technology [8] has been used in every functional fields of energy like energy generation, energy storage and energy transfer.

Energy generation applications of nanotechnology are mostly improvement focused. Nanotechnology offers, for the first time, tools to develop new industries based on cost-effective and cost-efficient economies. This aspect of nanotechnology contributes sustainable economic growth. Miniaturization of materials implies not only size but also improved properties. Because of these specialties, nanotechnology has the potential to significantly reduce the impact of energy production, storage and use. This promising advantage of nanotechnology makes EU decide nano-energy as prior research field. Moreover, the contribution of nanotechnology can be seen in solar and hydrogen economies based on Serrano et al. (2009)'s literature review on sustainable energy [9].

The aim of this study is to evaluate the evolution of nano-energy field by analyzing the concept networks which have emerged in last decade. The study covered the 2005-2014 period and tested these research questions:

1. How can nanotechnology and energy relationship be interpreted based on the network visuals? 
2. How can the technological growth of nano-energy sub-fields be interpreted?

By answering these hypotheses it is aimed to determine the nano-energy technology trend by means of scientometrics. It is thought that visualizing and interpreting emerging trends of nanoenergy keywords will add important value to existing literature for designing future scenarios.

After introducing the subject in the first section, nanotechnology and energy relationship literature is reviewed in the second section by examining review studies regarding nano-energy. Moreover, scientometric and bibliometric studies on nano-energy also reviewed in the same section to understand the adding value of this study to existing literature. In the third section lexical search query strategy is explained and data obtained from the Web of Science database. After cleaning data scientometric analysis and network analysis is performed and findings presented. Finally in the conclusion section findings are discussed and future research direction is interpreted based on the literature and explored trends.

\section{NANO-ENERGY LITERATURE}

Nanotechnology is technology at the nanometer scale-the scale of atoms and molecules. A nanometer is one-billionth of a meter, or the length of about three to twenty atoms. Nanoscale particles are not new, but only in recent decades have scientists been able to truly visualize and control nanoscale phenomena. The vision of the technological promise of manipulating matter at the nanoscale is often referred to Nobel-Prize-winning physicist Richard Feynman, who famously argued in 1959 that "there is plenty of room at the bottom" for applications such as nanoscale circuits and nanomedicine. Since then, researchers have produced extraordinary breakthroughs in nanoscale science and engineering with widespread applications.

One of the field that nanotechnology mostly applied is energy. Growing number of scientists and engineers are exploring and manipulating material properties at an atomic scale to create designer 
materials, which might ultimately increase the efficiency of current energy sources or make new energy sources on a commercial scale [10].

Nanotechnology applied most of the energy types for different purposes. For example, different physical properties of materials in nanoscale are searched for finding new catalysts to improve energy efficiency of cracking fossil fuels. However, because of the lack of sustainability aspect, there is not much studies regarding fossil fuels.

Moreover, according to Serrano et al. (2009) most promising application fields for the energy domain are mainly focused on solar energy, hydrogen conversion and thermoelectric devices [9]. A recent review in Science concluded that integrating graphene into solar cells and batteries holds promise for improved energy conversion and storage, but that "further improvement of highvolume manufacturing and transfer processes multilayered heterostructures is needed." The inclusion of nanoscale components in Photovoltaic (PV) cells is a way to reduce some limitations as ability to control the energy bandgap and enhance the effective optical path and decrease the probability of charge recombination. Nanocrystal quantum dots [11], Doped $\mathrm{TiO}_{2}$, dye-sensitized solar cells [12], fourth generation PVs, polycyristalline-Si/doped $\mathrm{TiO}_{2}$ [13] are the most promising nano intersections for solar energy.

Another issue is that nanotechnology mostly applied in hydrogen field. Hydrogen may be accepted as energy storing and transporting technology. Hydrogen is only produced and stored, unlike other renewables which are needed to be transformed to electricity for being transported. Because of this aspect, hydrogen may be considered as an energetic vector. There are electrolysis methods to part water into hydrogen and oxygen but it consumes significant amount of electricity and thus increases costs. However, Nanophotocatalysis is the most promising method for producing hydrogen economically. 
Moreover, main bottleneck for hydrogen energy is transportation. Chemisorption techniques have the drawback of binding hydrogen too tightly and physisorption suffers from low-temperature adsorption. Carbon nanotubes are again most promising technology for hydrogen storage and transportation. The fuel cells for hydrogen storage have many different electrolytes and these electrolytes make these fuel cells' names as, Polymer Electrolyte Membrane Fuel Cell (PEMFC), Phosphoric Acid Fuel Cell (PAFC), Alkaline Fuel Cell (AFC), Molten Carbonate Fuel Cell (MCFC) and Solid Oxide Fuel Cell (SOFC).

At last it can be said that nanotechnology and energy crossed with solar, hydrogen, and battery development. There are some bibliometric and scientometric studies on nano-energy in the literature. First one is about measuring scientific research in the field by Guan and Liu (2014) [7]. They explored the scientific research profile of nano-energy during 1991-2012 based on bibliometrics and social network analysis. They found that even world publications indicate exponential growth pattern, USA, Germany, England, France, and Japan display decreasing research trends. China, India and South Korea demonstrate a rise in terms of the world share. Consequently, they proposed that emerging economies can earn competitive advantages in some emerging fields by properly engaging a catch-up strategy.

Another study is about nano-energy in China again by Liu and Guan (2015) [14]. They tried to examine how entire networks change over time in their study. They found that the subsequent growth and diversity of ego networks are caused by three coexisting driving forces (as collaborative capacity, network status position and cohesion) that act collectively.

Invention profiles and uneven growth of technological knowledge in the emerging nano-energy field is studied by Guan and Liu (2015) [15]. Because patent data is used, this study is different from others. Based on their results nano-energy patented inventions mainly come from a combinatorial process with a very limited role of developing brand new technological 
capabilities. Reusing existing technological capabilities, including recombination reuse, recombination creation and single reuse is the primary source of inventions. From this perspective, it can be assumed that inventors and managers should not only consider their own technological knowledge but also should take seriously of the technological knowledge owned by others.

Finally it can be seen that nanotechnology and energy fields have many intersections in the reviewed literature and potentially it will be many in the future. The literature of this field is analyzed by using bibliometric methods by Guan and Liu in several studies but these studies are not mentioning the conceptual evolution of this relationship. Because of this, it is thought that this study will contribute to the existing literature by evaluating the evolution of the relationship between nanotechnology and energy year to year basis.

\section{METHODOLOGY}

There are four stages in this study which are: 1) data retrieval, 2) data cleaning and optimization, 3) data analysis and 4) data visualization. All these stages are significant to the result of the study and one of the biggest challenges in bibliometrics and scientometrics analyses is to gather the required data by selecting the appropriate terms for the search so that the data set includes the relevant documents and excludes unnecessary ones, thus increasing the validity of the research. Moreover, it is an even greater challenge if the analysed field is an emerging technology and there are many similar terms that are used by other technologies.

For that reason, at the first stage for gathering data, nanotechnology and energy data are handled as two main sets. Nanotechnology set is gathered by using Arora et al's (2013) refined search keywords and found related publications with this keyword set as shown in Table 1 [5]. As can

be seen in Table 1 eight set is used for retrieving nanotechnology publications and at last by using 
OR Boolean operator these sets combined. These search terms are used on academic journal databases and all the relevant data is collected.

Table 1: Nanotechnology Search Keywords and Retrieved Publications [5]

\begin{tabular}{|c|c|c|}
\hline Set & $\begin{array}{c}\text { \#of } \\
\text { Publications }\end{array}$ & \\
\hline \# 9 & 212,937 & \#8 OR \#7 OR \#6 OR \#5 OR \#4 OR \#3 OR \#2 OR \#1 \\
\hline \# 8 & 39,181 & $\begin{array}{l}\text { TS=((biosensor*) OR (sol gel* or solgel*) OR (dendrimer*) OR (soft lithograph*) OR } \\
\text { (molecular simul*) OR (quantum effect*) OR (molecular sieve*) OR (mesoporous material*) } \\
\text { AND (MolEnv-R) NOT (nano*)) }\end{array}$ \\
\hline \# 7 & 16,027 & $\begin{array}{l}\text { TS=(SELF ASSEMBL*) OR TS=(SELF ORGANIZ*) OR TS=(DIRECTED ASSEMBL*) } \\
\text { AND TS=(MolEnv-I) NOT TS=(nano*) }\end{array}$ \\
\hline \# 6 & 7,377 & $\begin{array}{l}\text { SO = ((Fullerene* OR IEEE Transactions on Nano* OR Journal of Nano* OR Nano* OR } \\
\text { Materials Science Engineering C* OR ACS Nano OR Current Nanoscience OR Digest Journal } \\
\text { of Nanomaterials and Biostructures OR IEE Proceedings Nanobiotechnology OR IET } \\
\text { Nanobiotechnology OR International Journal of Nanomedicine OR International Journal of } \\
\text { Nanotechnology OR Journal of Biomedical Nanotechnology OR Journal of Computational and } \\
\text { Theoretical Nanoscience OR Journal of Experimental Nanoscience OR Nature Nanotechnology } \\
\text { OR Photonics and Nanostructures* OR Wiley Interdisciplinary Reviews Nano*) NOT nano*) }\end{array}$ \\
\hline \# 5 & 338 & $\begin{array}{l}\text { TS = (((NEMS OR Quasicrystal* OR "quasi-crystal*" OR "quantum size effect" OR "quantum } \\
\text { device"AND MoleEnv-I) NOT nano*)) }\end{array}$ \\
\hline \# 4 & 65,828 & $\begin{array}{l}\text { TS=((TEM OR STM OR EDX OR AFM OR HRTEM OR SEM OR EELS) OR (atom* force } \\
\text { microscop*) OR (tunnel* microscop*) OR (scanning probe microscop*) OR (transmission } \\
\text { electron microscop*) OR (scanning electron microscop*) OR (energy dispersive X-ray) OR (X- } \\
\text { ray photoelectron*) OR (xray photoelectron*) OR (electron energy loss spectroscop*) OR } \\
\text { (enhanced raman-scattering) OR (surface enhanced raman scattering) OR (single molecule } \\
\text { microscopy) OR (focused ion beam) (ellipsometry) OR (magnetic force microscopy) AND } \\
(\text { MolEnv-I) NOT (nano*)) }\end{array}$ \\
\hline \# 3 & 48,122 & $\begin{array}{l}\left.\text { TS=((((molecul* motor*) or (molecul* } \text { ruler }^{*}\right) \text { or (molecul* wir*) or (molecul* devic*) or } \\
\text { (molecular engineering) or (molecular electronic*) or (single molecul*) or (fullerene*) or } \\
\text { (buckyball) or (buckminsterfullerene) or (C60) or (C-60) or (methanofullerene) or } \\
\text { (metallofullerene) or (SWCNT) or (MWCNT) or (graphene) or (dye-sensitized solar cell) or } \\
\text { (DSSC OR ferrofluid*) or (coreshell) or (coulomb blockad*) or (bionano*) or (langmuir- } \\
\text { blodgett) or (Coulombstaircase*) or (PDMS stamp*) not nano*))) }\end{array}$ \\
\hline \# 2 & 7,961 & TS = ((“quantum dot*”, OR “"quantum well*”' OR “'quantum wire*”) NOT nano*) \\
\hline \# 1 & 117,219 & TS $=($ nano* $)$ \\
\hline
\end{tabular}


To retrieve nano-energy related data, it is thought to focus on the energy publications by using the core journal list of Web of Science under the heading of Energy \& Fuels. Then, experts in the energy field are consulted for verifying the journal list and as a result the final list is gathered as shown in Table 2.

Table-2: Energy Journal Query List

SO=(“ADVANCED ENERGY MATERIALS” OR “APPLIED ENERGY” OR “APPLIED THERMAL ENGINEERING” OR "BIOENERGY RESEARCH” OR “BIOFUELS BIOPRODUCTS \& BIOREFINING-BIOFPR” OR “BIOMASS \& BIOENERGY” OR “BIORESOURCE TECHNOLOGY” OR “BIOTECHNOLOGY FOR BIOFUELS” OR “CHEMICAL ENGINEERING AND PROCESSING” OR “CHEMISTRY AND PHYSICS OF CARBON” OR “CHEMISTRY AND TECHNOLOGY OF FUELS AND OILS” OR “CHINA PETROLEUM PROCESSING \& PETROCHEMICAL TECHNOLOGY” OR “COMBUSTION AND FLAME” OR “COMBUSTION EXPLOSION AND SHOCK WAVES” OR “COMBUSTION SCIENCE AND TECHNOLOGY” OR “COMBUSTION THEORY AND MODELLING” OR “CT\&F-CIENCIA TECNOLOGIA Y FUTURO” OR “ENERGIES” OR “ENERGY” OR “ENERGY \& ENVIRONMENTAL SCIENCE” OR “ENERGY \& FUELS” OR “ENERGY AND BUILDINGS” OR “ENERGY CONVERSION AND MANAGEMENT” OR “ENERGY EFFICIENCY” OR “ENERGY EXPLORATION \& EXPLOITATION" OR “ENERGY FOR SUSTAINABLE DEVELOPMENT” OR “ENERGY JOURNAL” OR “ENERGY POLICY” OR “ENERGY SOURCES PART A-RECOVERY UTILIZATION AND ENVIRONMENTAL EFFECTS” OR “ENERGY SOURCES PART B-ECONOMICS PLANNING AND POLICY” OR "ENERGY TECHNOLOGY” OR “FUEL” OR “FUEL CELLS” OR "FUEL PROCESSING TECHNOLOGY” OR “GEOTHERMICS” OR “GLOBAL CHANGE BIOLOGY BIOENERGY” OR “GREENHOUSE GASES-SCIENCE AND TECHNOLOGY” OR “IEEE JOURNAL OF PHOTOVOLTAICS" OR "IEEE TRANSACTIONS ON ENERGY CONVERSION" OR "IEEE TRANSACTIONS ON SUSTAINABLE ENERGY” OR “IET RENEWABLE POWER GENERATION” OR “INTERNATIONAL JOURNAL OF COAL GEOLOGY” OR “INTERNATIONAL JOURNAL OF COAL PREPARATION AND UTILIZATION” OR “INTERNATIONAL JOURNAL OF ENERGY RESEARCH” OR “INTERNATIONAL JOURNAL OF EXERGY” OR “INTERNATIONAL JOURNAL OF GREEN ENERGY” OR "INTERNATIONAL JOURNAL OF GREENHOUSE GAS CONTROL” OR “INTERNATIONAL JOURNAL OF HYDROGEN ENERGY” OR "INTERNATIONAL JOURNAL OF OIL GAS AND COAL TECHNOLOGY” OR “INTERNATIONAL JOURNAL OF PHOTOENERGY” OR "INTERNATIONAL JOURNAL OF VENTILATION" OR “JOURNAL OF BIOBASED MATERIALS AND BIOENERGY” OR "JOURNAL OF CANADIAN PETROLEUM TECHNOLOGY” OR “JOURNAL OF ENERGY CHEMISTRY” OR “JOURNAL OF ENERGY ENGINEERING” OR “JOURNAL OF ENERGY IN SOUTHERN AFRICA” OR “JOURNAL OF ENERGY RESOURCES TECHNOLOGY-TRANSACTIONS OF THE ASME” OR “JOURNAL OF FUEL CELL SCIENCE AND TECHNOLOGY” OR “JOURNAL OF MATERIALS CHEMISTRY A” OR "JOURNAL OF NATURAL GAS SCIENCE AND ENGINEERING” OR “JOURNAL OF PETROLEUM SCIENCE AND ENGINEERING” OR “JOURNAL OF POWER SOURCES” OR “JOURNAL OF RENEWABLE AND SUSTAINABLE ENERGY” OR “JOURNAL OF SOLAR ENERGY ENGINEERING-TRANSACTIONS OF THE ASME" OR “JOURNAL OF THE ENERGY INSTITUTE” OR “JOURNAL OF THE JAPAN PETROLEUM INSTITUTE” OR “OIL \& GAS JOURNAL” OR “OIL \& GAS SCIENCE AND TECHNOLOGY-REVUE D IFP ENERGIES NOUVELLES” OR “OIL GAS-EUROPEAN MAGAZINE” OR “OIL SHALE” OR "PETROLEUM CHEMISTRY" OR "PETROLEUM EXPLORATION AND DEVELOPMENT" OR “PETROLEUM SCIENCE” OR "PETROLEUM SCIENCE AND TECHNOLOGY” OR “POWER” 
OR "PROCEEDINGS OF THE COMBUSTION INSTITUTE" OR "PROCEEDINGS OF THE INSTITUTION OF CIVIL ENGINEERS-ENERGY" OR “PROGRESS IN ENERGY AND COMBUSTION SCIENCE” OR "PROGRESS IN PHOTOVOLTAICS" OR “RENEWABLE \& SUSTAINABLE ENERGY REVIEWS" OR “RENEWABLE ENERGY” OR “SOLAR ENERGY” OR "SOLAR ENERGY MATERIALS AND SOLAR CELLS” OR “SOLID FUEL CHEMISTRY” OR “SPE RESERVOIR EVALUATION \& ENGINEERING” OR “UTILITIES POLICY” OR “WILEY INTERDISCIPLINARY REVIEWS-ENERGY AND ENVIRONMENT” OR “WIND ENERGY”)

As can be seen in Table 2 there are 88 journals in the list and retrieved 162.236 publications. Then nanotechnology set and energy set are crossed for finding the intersection. Final publication number is 25.999 and all these data are imported into the VantagePoint software by using their filters to save and transform all into the structured format where analyses can be performed. The filters in VantagePoint are designed according to the different types of databases and so all the important parts of the papers are collected under one category such as abstracts of the papers. After retrieving data as full record from web of science database, data cleaning process is started. In the cleaning part all unnecessary papers or words are removed. For example, duplicate papers are removed with significance of similarity level between their abstracts and titles. Also, some unnecessary words are removed as there are many common words that are used in the literature which are not significant to the study and so these words are cleaned by the stop words list. To do that, the current stop words list is updated with additional words to eliminate unnecessary words and have all nano-energy related terms before the actual analysis started.

For the first research question ten visual is produced by using author keywords. Keyword cooccurrence matrix is generated by using the Vantagepoint software where text mining related techniques are used such as how one word appears with another and in general to the all other texts such as TF-IDF. Afterwards, the results of the matrix related calculations are exported to UCINET for calculating centrality measures based on degree centrality (degree, closeness, and betweenness are calculated). These measures are completed to see the relevance of different subjects with each other such as how one subject has relevance to another in nano-energy. After 
calculating the centrality measures for better visualization the Pajek formatted file used in VosViewer to produce heat maps. Time dimension is added by using edge matrix in UCINET. Visualization of results allowed us to interpret the convergence between nanotechnology and energy fields.

\section{DATA ANALYSIS AND FINDINGS}

Retrieved data is cleaned and the maps are produced. Author keywords are used for analysis. The heat maps are interpreted with three-year periods to enhance the visual results for better understanding. First period is for 2005-2007 and demonstrated in Fig.1. 


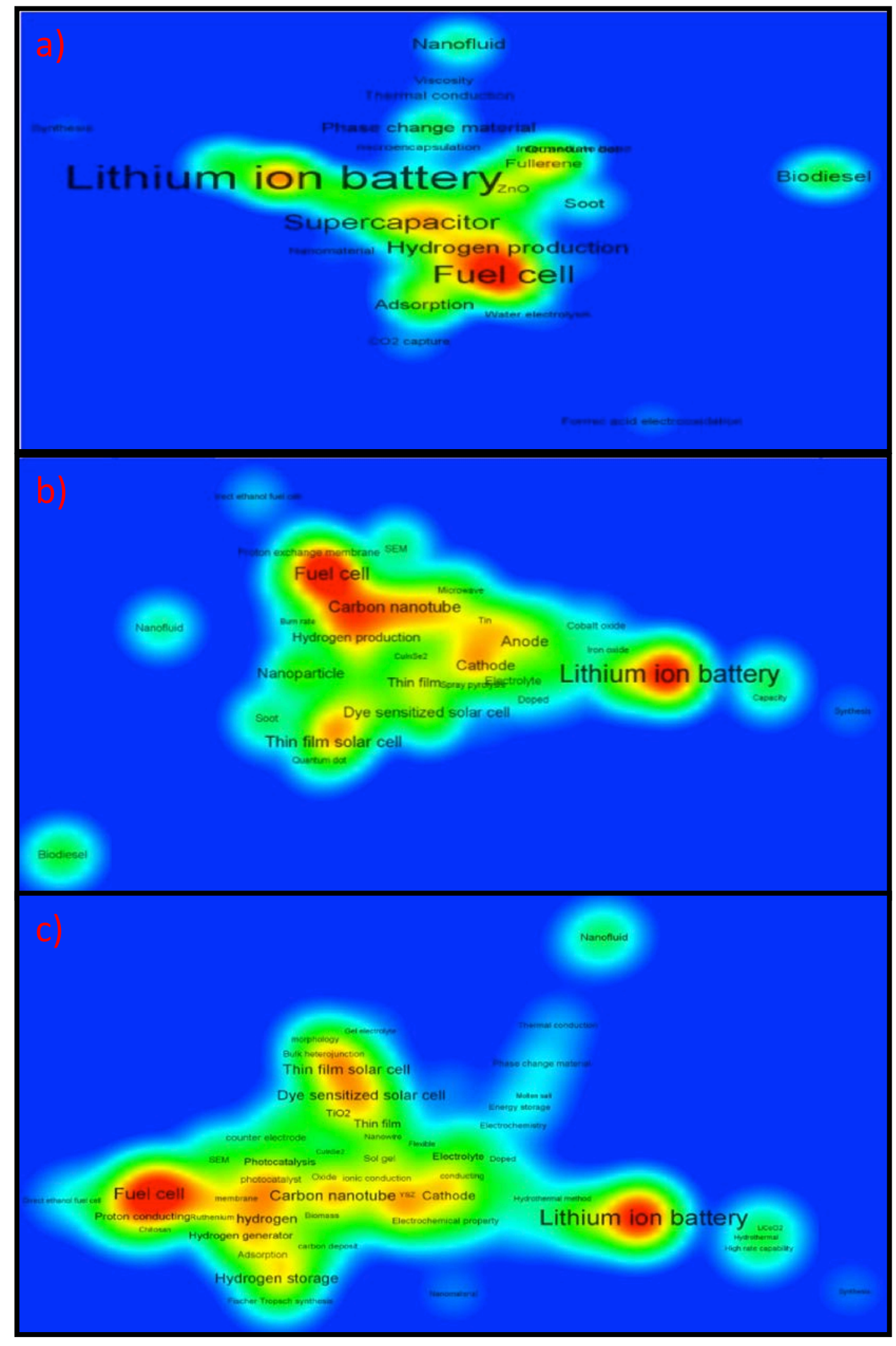

Figure 1: Heat Maps for 2005 (a), 2006 (b), 2007 (c) 
When the heat maps in Figure 1 interpreted it can be said that main theme for 2005 is fuel cells. There are some studies on nanofluids and biodiesel as separate islands also. Main island in 2005 consists supercapacitors, solar cells, fullerene, and $\mathrm{ZnO}$, adsorption, $\mathrm{CO} 2$ capture. Supercapacitors appear here as one of the key terminology as some of the nanostructures such as graphene, nanowires and CNTs led to efficient energy storage. As renewable energy related research is one of the key area in energy field and one of the key problem is the storage systems, these new nanostructures have great offerings for the future of renewable energy related studies. Lithium ion batteries (LIBs) are another key term as shown in all heat maps in the rest of the study. LIBs are the most popular batteries for the electronics sector due to its size and capacity. However, there are still various problems exist with regards to the capacity, charging time and longevity of LIBs. Nanoengineering can improve the characteristics of materials by offering higher surface areas at nanoscale and this can lead to better storage and faster in-out delivery time of charge.

2006 has an additional concept like carbon nanotubes, Dye-sensitized solar cells, Thin film solar cells, PEMS. However, nanofluid and biodiesel are again in different islands. Dye-sensitized solar cells and thin-film solar cells are both improved solar cells to create a better surface to increase light absorption (dye). Although, quantum dots are also popular nanostructures for the purpose of dye, they appear to lag behind based on the heat map. 2007 may be accepted the resolution of the sub-fields as battery technologies, hydrogen, and solar cells. There are more keywords than other years in 2007 but the focus of subjects remain same in general. 


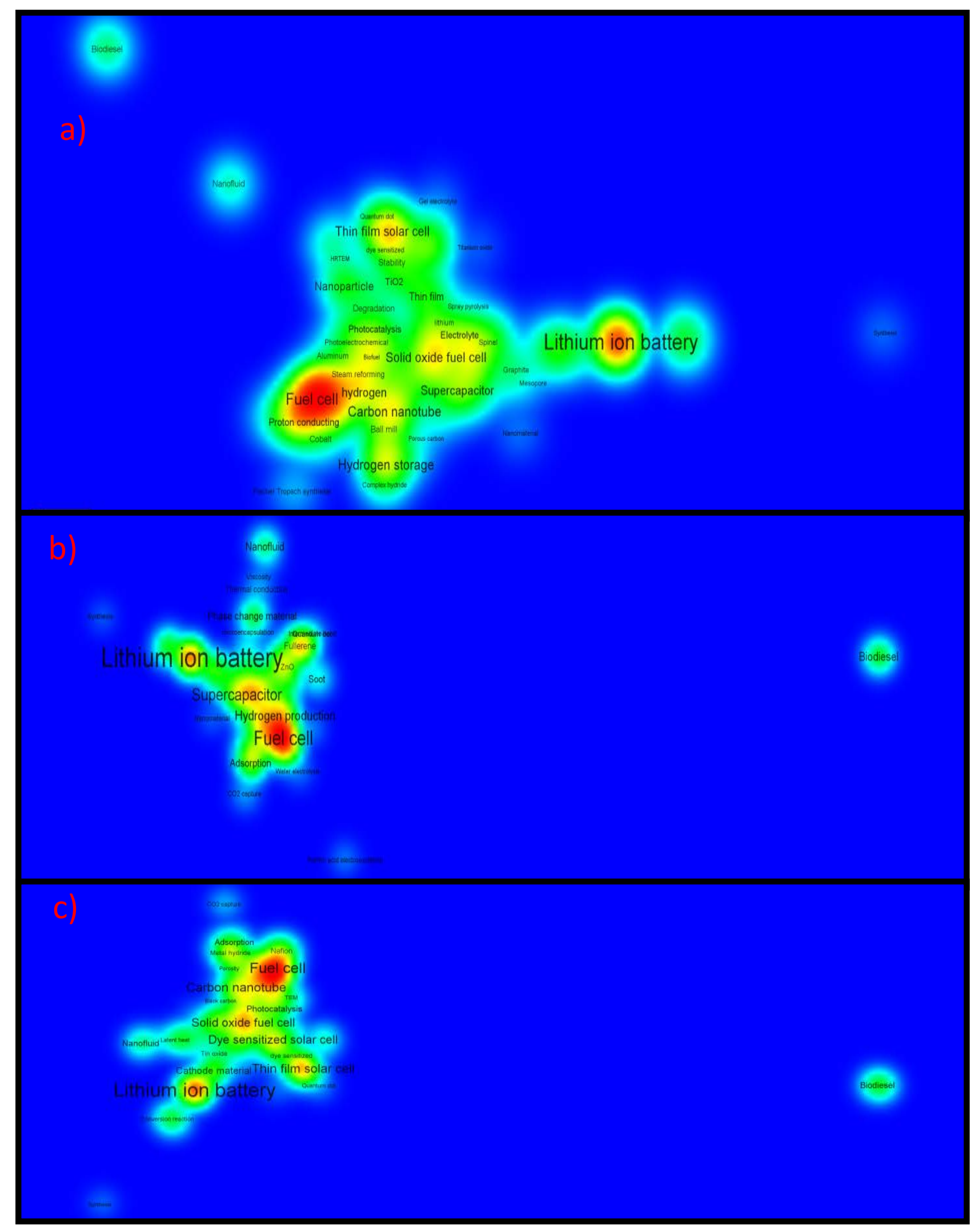

Figure 2 Heat Maps for 2008 (a), 2009 (b), 2010 (c) 
In figure 2, the second period is analyzed for the years 2008, 2009 and 2010. After interpreting first period, it can be seen in the fig.2 that concepts are more convergent than first period. For the 2008 Nanoparticle is appearing near solar cell cluster and solid oxide fuel cell revealed. Hydrogen storage is becoming a new island in 2008. There is not much change in 2009 except hydrogen production as a new concept that appeared in the middle of heat map. 2010 is covering nanofluids near the solar cell cluster and quantum dot is appeared near the thin film solar cell.

Last period consists four years as 2011, 2012, 2013 and 2014 as shown in Figure 3. 


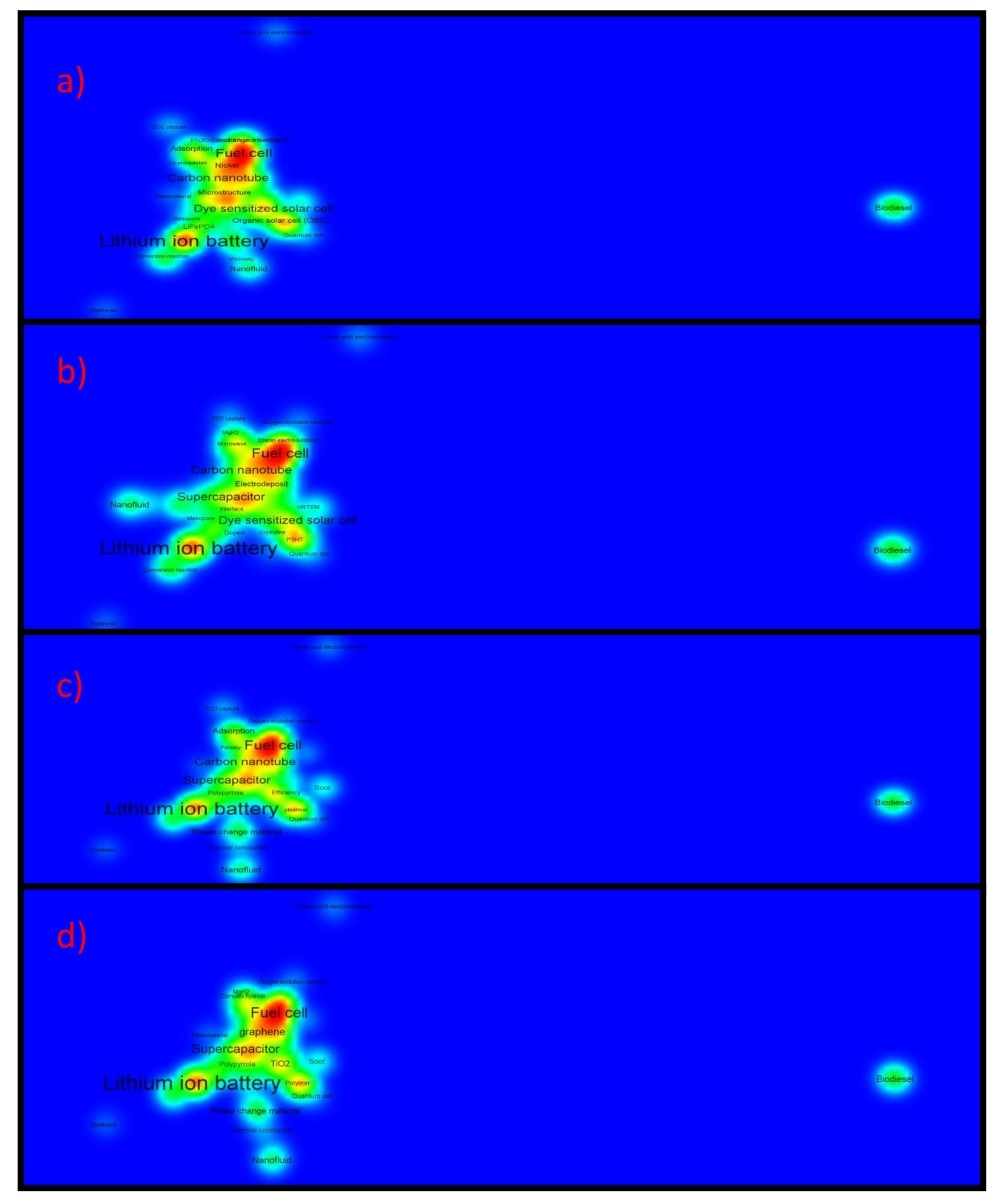

Figure 3: Heat Maps for 2011 (a), 2012 (b), 2013 (c), 2014 (d) 
The keywords in the last period are mostly similar and some of the technology fields are thought to be matured. Only distinction may be the location of nanofluid and phase change material. From 2011 to 2014 nanofluid departed from the main island and appearing as a distinct island.

\section{CONCLUSION}

This study focused on the relationship between energy and nanotechnology fields with the help of heat maps that are generated by using the scientometrics method. The period between 2005 and 2014 shows that there is a great convergence between nanotechnology and energy field as there were rapid changes in the number of nanotechnology terminology with energy concepts that were used in the academic literature that is analyzed.

As shown in other studies and the heat maps that are generated in this study, nanostructures appear to be the future of energy field. Current energy technologies seem to be reaching its capacity due to the materials that are available in the industry. Nanoengineering and nanostructures, especially with physical improvement of surface of materials can lead to solutions in energy storage related areas and so many problems in electronics sector.

The findings of this study provide a great snapshot of trending areas that were discussed in the literature review of other studies. Some of these literatures were related to the hydrogen, photovoltaic and dye-sensitized solar cells and where they emerge with each other and nanotechnology field. Accordingly, CNTs, thin films and graphene appear as the most popular nanostructures where there is a great convergence between nanotechnology and energy field.

This study showed the relationship between nanotechnology and energy field based on the academic literatures by using the collection of energy related literature. This study can be enhanced in a following study where a large patent data is analyzed with the same method to compare the results. The limitations of this study could be related to the long tail problem as 
discussed in any statistical or data-mining related study. Accordingly, the visuals in heat maps are presenting the most popular areas where convergence occur but by focusing only on newly emerging areas or by eliminating highly obvious ones (such as hydrogen) may lead to an in-depth look into the areas where new developments occur. 


\section{References}

[1] Wang, Z.L. and Wu W. (2012) Nanotechnology-Enabled Energy Harvesting for SelfPowered Micro-/Nanosystems. Angew. Chem. Int. Ed. 2012, 51, 2-24.

[2] Jones, R. (2009) Nanotechnology, energy and markets. Nature Nanotechnology, Vol.4, February, www.nature.com/naturenanotechnology

[3] Tegart, R. (2009) Energy and nanotechnologies: Priority areas for Australia's future. Technological Forecasting\&Social Change, 76, 1240-1246.

[4] Roadmaps for Nanotechnology in Energy, The Institute for Nanotechnology, Edinburgh, 2006.

[5] Arora, S. K., Porter, A. L., Youtie, J., Shapira, P. (2013). “Capturing new developments in emerging technology: an updated search strategy for identifying nanotechnology research outputs”. Scientometrics, 95, 351-370.

[6] Arora, S. K., Youtie, J., Carley, S., Porter, A. L., \& Shapira, P. (2014). "Measuring the development of a common scientific lexicon in nanotechnology”. Journal of Nanoparticle Research, 16, 1-11.

[7] Guan, J., Liu, N. (2014) Measuring scientific research in emerging nano-energy field. J Nanopart Res, 16:2356, 1-15.

[8] Kreuchauff, F., Teichert, N. (2014) Nanotechnology as general purpose technology. Working Paper Series in Economics No.53, KIT, ISSN: 2190-9806.

[9] Serrano, E., Rus, G., Garcia-Martines, J. (2009) Nanotechnology for sustainable energy. Renewable and Sustainable Energy Reviews, 13, 2373-2384.

[10] Guo, K.W. (2012) Green nanotechnology of trends in future energy: a review. International Journal of Energy Research, 36, 1-17. 
[11] Ross RT, Nozik AJ. (1982). Efficiency of hot-carrier solar energy converters. J Appl Phys, 53, 3813-3818.

[12] O’Regan, B., Gratzel, M. (1991). A low-cost, high-efficiency solar cell based on dyesensitized colloidal TiO2 films. Nature, 353, 737-740.

[13] Takabayashi S, Nakamuraa R, Nakato Y. (2004). A nano-modified Si/TiO2 composite electrode for efficient solar water splitting. J Photochem Photobiol A Chem, 166, 107-113.

[14] Liu, N., Guan, J. (2015) Dynamic evolution of collaborative networks: evidence from nanoenergy research in China. Scientometrics, 102, 1895-1919.

[15] Guan, J., Liu, N. (2015) Invention profiles and uneven growth in the field of emerging nanoenergy. Energy Policy, 76, 146-157. 